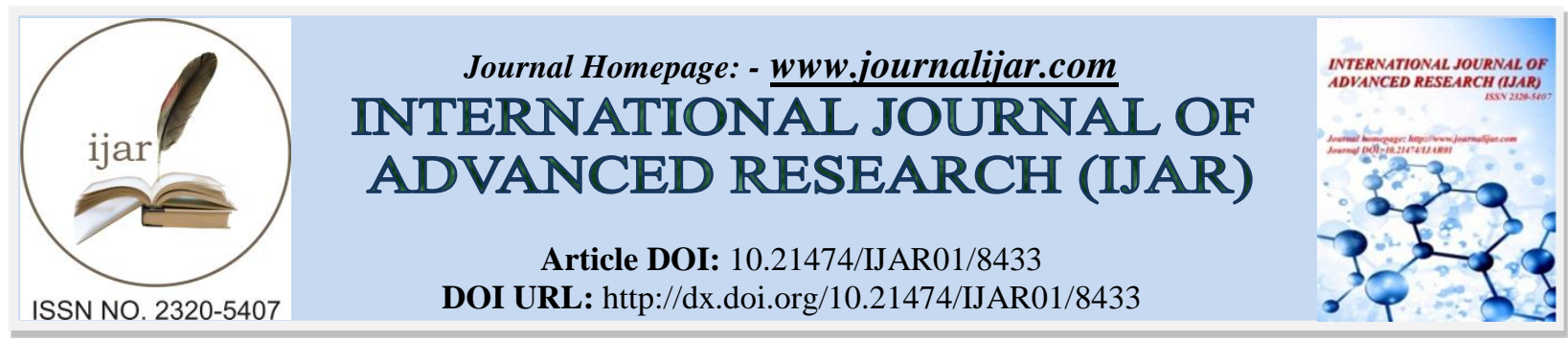

RESEARCH ARTICLE

\title{
CONSTRUCTING COLLABORATIVE LEARNING COMMUNITIES OF TEACHERS: A CASE STUDY IN PORTUGAL.
}

Ana Maria Costa e Silva, Rosalinda Herdeiro and Sílvia Cunha.

Centre for Studies of Communication and Society (CECS), University of Minho, Portugal.

\section{Manuscript Info}

Manuscript History

Received: 18 November 2018

Final Accepted: 20 December 2018

Published: January 2019

Key words:-

Communities of practice, collaborative learning, teacher work, collaborative workplace.

\begin{abstract}
The work and collaborative learning of teachers are recognized, as fundamental factors in the professional development of teachers and in the quality of educational organizations. This text presents some results of a case study carried out in a Group of Schools in the north of Portugal staffed by 134 teachers of various educational levels by means of a qualitative and quantitative methodology. The objectives of the investigation focused on understanding the way that the teachers described their learning opportunities, recognized the facilitating and inhibiting elements of collaborative professional learning in the workplace and analyzed the way how the teachers perceived their professional learning in the work place. Information was collected by recourse to an enquiry using a questionnaire and semi-structured interviews. Fundamentally we focused on results of a qualitative nature with particular attention to information resulting from the interviews and also from the questionnaires. The results showed the recognition on the part of the teachers of the ways and contexts of collaborative work and learning and their importance in their professional daily life and quality of work. They also reflected that, although the teachers recognized these contexts in their current professional experience, they did not associate these experiences directly to communities of practice.
\end{abstract}

Copy Right, IJAR, 2018,. All rights reserved.

\section{Introduction:-}

In communities of practice and collaborative learning the participants join forces spontaneously not only with the objective of sharing common interests but essentially to talk about their activities and work in a collaborative way concerning practices that boost their learning and benefit their professional performance.

The transformation of the knowledge society and the different needs of citizens create new and diverse challenges for governments and schools, which demand ever more complex and rigorous responses that plan for both quality and equity in education.

The publication Repensar a Educação (UNESCO, 2016) asserts that education must prepare citizens and communities for the tensions created by such transformations by giving them the capacity of getting used to them and responding to them. Adding still that education must find different ways of responding to the challenges, not

Corresponding Author:-Ana Maria Costa e Silva.

Address:-Centre for Studies of Communication and Society (CECS), University of Minho, 
only with new practices, but also with new perspectives that permit an understanding of the nature of learning and the role of knowledge in human development.

In turn, the document Educação 2030 - Declaração de Incheon, which was organized by various international institutions, established a new vision for education founded "on the expansion of access, inclusion and equity, as well as on the quality and results of learning at all levels within the scope of an approach based on learning throughout life" (UNESCO et al., 2016, p. 6). In this sense, it becomes imperative to rethink the role of education and teacher training by emphasizing the way how schools organize learning and how teachers learn.

In accordance with the observation of Justino (2010, p. 115), it is not in an "extremely rigid, centralized, bureaucratic and homogenized system" that schools will find responses for the challenges in which they find themselves. Therefore, "to the traditional educational uniqueness it is necessary to find an alternative, which is recognized by the diversity of its educational response" with the aim of attaining more and better education for everyone (Justino, 2010, p. 115) supported, essentially, by collaborative teacher learning. In this sense, a culture of permanent learning, the social construction of knowledge and the practice of collaborative learning are required, thus, driving a new paradigm of professional training that gives importance to communities of practice and to the corresponding dynamics of collaborative learning. Collaborative teacher work implies the existence of formal and/or informal spaces and moments of discussion that permit an exchange of professional experiences and knowledge.

In this text we present experiences from a group of Portuguese schools from perceptions and happenings reported by teachers involved in a community of practice that stimulated sharing and teacher learning. Also mentioned are the spaces of teacher learning, particularly informal ones, which were provided to be more susceptible for building trust and the sharing of knowledge between teachers.

\section{Methodology: objectives, methods and sample Objectives and Methods:-}

The reported investigation was included in a project about collaborative professional teacher learning carried out in Portugal and Chile. The main objectives of the investigation undertaken were: i) to understand the way the teachers described the formal and informal opportunities for sharing in their school and what effects these had at the level of their practice; ii) to get to know the facilitating and inhibiting elements of collaborative professional learning in the work place; and iii) to analyze how teachers put into perspective their professional learning in their work place.

The study was focused on an investigation of a qualitative and quantitative nature (Bryman, 1988) using case study methodology (Yin, 1994; Stake, 1995) and it highlights the results of such a study carried out with teachers in a School Group situated in the northern zone of Portugal.

Three instruments were chosen for the collection of information: a) an information sheet describing the character of the School Group; b) a Likert-type scale questionnaire with 13 items, which was administered to all of the teachers and educators of the Group; and c) a protocol of a semi-structured interview with a manual for the questions, which was previously made available to the Director of the Group and eight teachers identified as key informants.

The analysis of the data from the questionnaires was accomplished with the help of SPSS statistical software, which was focused on a predominantly descriptive analysis. For the analysis of the content of the interviews the researchers turned to the previous categories and emerging categories that were determined by the research group.

\section{Sample}

The School Group, where the study was carried out, is a public institution located in a suburban area in the north of Portugal. This Group is composed of a basic school network with classes at junior secondary (junior high school) and secondary (high) school levels and four classes of primary (first) school and eight more primary (first) schools with pre-school (kindergarten) classes situated in various townships of the council district. The School Group had a total of some 1500 students and 134 teachers distributed in different professional categories, as shown in Table 1, which indicates that about $71 \%$ of the teachers belonged to the permanent staff of the Vila Flor Group of schools.

Table 1:-Distribution of teachers of the Group by professional category

\begin{tabular}{|l|l|l|l|l|l|}
\hline \multirow{2}{*}{ School Year } & CATEGORY & \multicolumn{4}{|l|}{} \\
\cline { 2 - 6 } & Permanent & School zone & Contracted & Others (technical & Total \\
\hline
\end{tabular}




\begin{tabular}{|l|l|l|l|l|l|}
\hline & full-time staff & staff & staff & specialists) & Annual \\
\hline $2016 / 2017$ & 95 & 21 & 16 & 3 & 134 \\
\hline
\end{tabular}

Of the 134 teachers, 95 (71\% of the total) responded to the questionnaire and of these the majority were female (76\%) with some $50 \%$ teaching in the primary (first) cycle. The largest number of respondents were in the age group of 40-49 years (37\%), followed by age group 30-39 years (30\%) and then $50-59$ years $(27 \%)$. $70 \%$ of these respondents possessed a first or bachelor degree and $28 \%$ were post-graduates of whom $17 \%$ held a master and eleven had a doctorate. A large majority of the respondents (80\%) belonged to the permanent staff of the Group and $50 \%$ had 20 or more years of service and of these $20 \%$ of them had more than 30 years. In summary, the response rate to the questionnaire is significant and the percentage of respondents by year of schooling is aligned with the total number of teachers in each cycle of schooling. Most of the teachers that responded to the questionnaire were female and had professional stability, as corroborated by the percentage of teachers, who belonged to the permanent staff and had worked for more than six years $(60 \%)$ in the Group.

Table 2 shows the main socio-demographic characteristics of the teachers interviewed.

Table 2:-Socio-demographic characteristics of teachers interviewed

\begin{tabular}{|l|l|l|l|l|l|}
\hline Code & Position & Age & Sex & $\begin{array}{l}\text { Years of } \\
\text { service }\end{array}$ & $\begin{array}{l}\text { Years working in the } \\
\text { Group }\end{array}$ \\
\hline PA & Director & 57 & M & 37 & 10 \\
\hline PB & 1st Cycle Coordinator & 52 & F & 30 & 8 \\
\hline PC & Language Coordinator & 47 & F & 20 & 8 \\
\hline PD & Science Coordinator & 52 & F & 25 & 12 \\
\hline PE & SHS* Coordinator & 53 & F & 28 & 15 \\
\hline PF & Expressive Arts** Coordinator & 46 & F & 22 & 10 \\
\hline PG & Pre-school Coordinator & 61 & F & 37 & 10 \\
\hline PH & Teacher of 1st cycle & 42 & M & 18 & 2 \\
\hline PI & Teacher of 2nd cycle & 39 & M & 18 & 15 \\
\hline
\end{tabular}

*Social and Human Sciences ** Includes Visual Arts and Handicrafts, Physical Education

(including dance) and Music

The teachers interviewed had diverse characteristics in terms of age, sex, years of service and areas and cycles of teaching.

\section{Results and discussion:-}

\section{Learning and Communities of Practice: the experiences of the teachers}

At the end of the last century the organizational theoretician Wenger (1998) defined Communities of Practice, as communities that brought together informally people associated by their common interests in learning and principally in the practical application of what was learned. Silva (2004), quoting McDermott (2000), added that communities of practice could be defined as a group of people that share and learn with each other by physical or virtual contact with the objective or necessity of resolving problems, exchanging experiences, techniques or methodologies and all with the purpose of considering the best practices.

In a general way, the teachers involved in this study claimed that experiences of communities of practice existed in their school, because they learned and developed themselves professionally through the sharing of materials and methodologies, the exchange of experiences, the joint resolution of problems and the appropriation of knowledge of common interest, independently of the places and moments in which they occurred. Put another way, the teachers felt themselves to be elements of a community of learning, because they shared perceptions in relation to what they do and what this means for their professional practices and for their school:

"(...) there have always been those moments for the sharing of ideas, what he had done the past year, what I would do this year, how they would evolve, if things would regress or not, so we have these moments, whether formal or informally, (...) this enriches me and improves the school." (PH) 
Furthermore, Meirinhos (2010), quoting Dillenbourg, Poirier and Carles (2003), adds that these communities can bring professionals together from one or various organizations, which allows them to collaborate generally, besides for tasks established by their own organizations. This aspect was mentioned also by the teachers, when they declared that they gathered together with some regularity with colleagues from other school groups to reflect on pedagogical practices. These experiences were much appreciated, as can be seen in the following comment:

“(...) we were at another school group to reflect and collaborate with the coordinators from other schools about articulation and school projects. This was a sharing at school council level (...) after classes. And I thought it very interesting and important for our practice (...)." (PE)

Figure 1 shows in a way articulated by the teachers, who participated in the interviews, how the characteristics of the communities of practice were defined by them, as they worked on the capacities that developed from the identified perceptions.

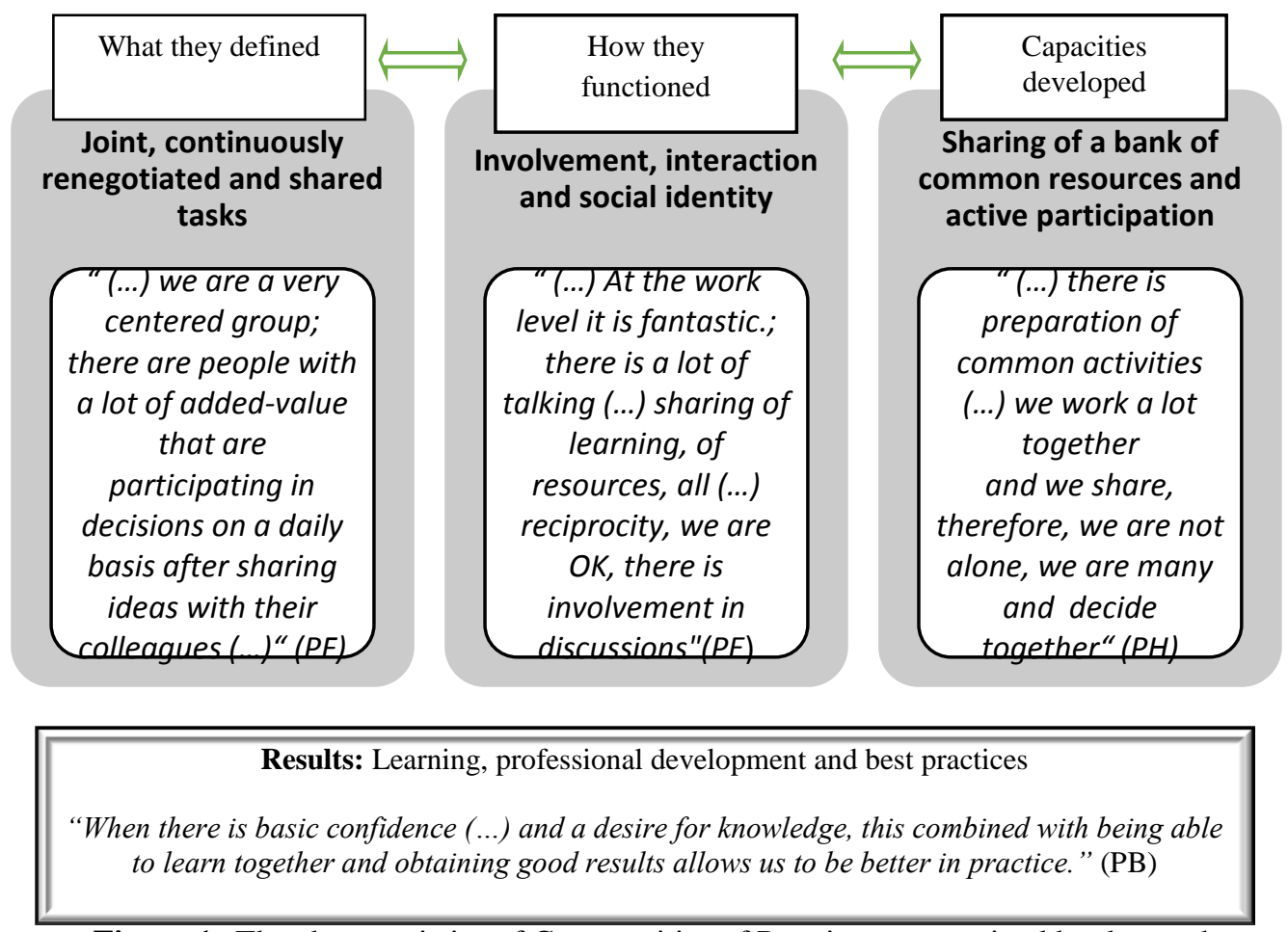

Figure 1:-The characteristics of Communities of Practice, as perceived by the teachers

Coll (2004) expounded that communities of practice presented similarities with communities of learning in so far as they refer to a group of people that involve themselves actively in collaborative processes for the resolution of problems depending upon simultaneously shared experience and knowledge, which is distributed among the members of a community. In reality, these similarities contribute towards the hesitation of some teachers in identifying the type of community in which they found themselves involved. Some responded by resorting to accounts of experiences contemplated in the circle of communities of learning:

“(...) a community?! (...) our own TEIP ${ }^{1}$ group made part of a community of learning with other TEIP neighbors (...). We, the directors, the TEIP coordinators made up part of eleven groups here in the North, we made up part of a community of learning, which reflected on various themes from time to time and we shared experiences (...).” (PB)

Others responded indicating their hesitation about speaking about their life experiences in communities of practice, thus revealing ignorance about the concept of a 'Community of Practice':

\footnotetext{
${ }^{1}$ The TIEP program concerns schools in areas that need help to improve the quality of education and success of student learning, to combat school drop-out and to create conditions favorable for educational guidance and a smooth transition into life after school in cooperation with other social organizations.
} 
“(...) we are going to do this, perhaps not consciously, in the sense (...) or maybe not in a more organized way (...) we are going to work on this (...) Yes, I think so.” (PC)

“(...) already we have this perspective of working in a community of ... I think so. I think that we, in my department, already we are working in a community. In a general way already we are working in a community. Now, we do not give it this name." (PD)

Alves, Queirós and Batista (2017, p. 176) pointed out that "the communities of practice must, in their way, be spaces of reflection in which one has time to analyze, produce, construct and reconstruct thoughts and ideas, through vigorous and pointed questioning by all participants", which should be independent of its identification or from immediate recognition (Wenger, 1998).

The communities of practice can present a variety of forms and dimensions, as well as different purposes and functions (Santos, 2012). However, the organization of a community of practice that strengthens collaborative learning implies the presence of requirements like: i) its composition and its centrality; ii) the manner of sharing of life experiences; iii) its integration in the institution; iv) the context of development; and, finally, v) the domain of interest (Santos, 2012).

The evident understandings in the interviews with the teachers emphasized various dimensions related to the organization of a community of practice by distinguishing a set of characteristics appropriate to the community to which they belonged. The following table systematizes the domains and characteristics identified by the teachers.

\begin{tabular}{|c|c|c|}
\hline Domains & Characteristics & Words of the teachers \\
\hline Who are they? & Teachers of the same cycle/subject & $\begin{array}{l}\text { "(...) we are a group of the first cycle in which we } \\
\text { basically all have to work together }(\mathrm{PH}) \\
\text { "I meet with colleagues of my subject, for these } \\
\text { informal meetings I meet with colleagues (...)." } \\
\text { (PE) }\end{array}$ \\
\hline $\begin{array}{l}\text { How do they } \\
\text { share? }\end{array}$ & Face-to-face and online sharing & $\begin{array}{l}\text { "I forward by email very frequently readings that are } \\
\text { printed in newspapers that I see, as well as readings } \\
\text { from books, articles and it stimulates me to read." } \\
\text { (PB) } \\
\text { "Every year, I do part of our annual plan of activities } \\
\text { for sharing experiences (...), all the teachers attend } \\
\text { and listen to each other in our auditorium." (PG) }\end{array}$ \\
\hline $\begin{array}{l}\text { What is the } \\
\text { framework? }\end{array}$ & $\begin{array}{l}\text { Curricular department and } \\
\text { informal/voluntary meetings }\end{array}$ & $\begin{array}{l}\text { "Even if it would be at lunch time, we speak (...) If } \\
\text { not we, manage to «look at it tomorrow or later in } \\
\text { the afternoon, in the interval or after the interval, we } \\
\text { stay on a little and we will analyze (..)." (PD) } \\
\text { "During the year there are departmental meetings in } \\
\text { which we discuss our anxieties, doubts, etc (...) we } \\
\text { learn and share with our colleagues." (PB) }\end{array}$ \\
\hline $\begin{array}{l}\text { In which context } \\
\text { do they } \\
\text { participate? }\end{array}$ & $\begin{array}{l}\text { Participation in school and in wider } \\
\text { networks }\end{array}$ & $\begin{array}{l}\text { "(..) I think that we learn much from each other. } \\
\text { Here inside school, I think that it is very important } \\
\text { that we learn inside }(\ldots) . "(\mathrm{~PB}) \\
\text { "Right now we meet in a network, where all the } \\
\text { schools participate at the school council level, (...) } \\
\text { We start right away with training, suggestions, it } \\
\text { rotates around all of the groups (...) and that was } \\
\text { achieved (...)." (PF) }\end{array}$ \\
\hline $\begin{array}{l}\text { What is the focus } \\
\text { of interest? }\end{array}$ & Practice and pedagogical relationships & $\begin{array}{l}\text { "(..) we finish by organizing any work, strategies } \\
\text { and have conversations more at the level of } \\
\text { preparation of activities, of how to write very } \\
\text { specific questions for the work behavior of the }\end{array}$ \\
\hline
\end{tabular}


students and for their learning." (PH)

Table 3:-The process of organization of a community of practice

In the organization of communities of practice, it is essentially important that they maintain their principal purpose: namely, to learn and to do. In this sense, it is important that the life experiences in communities of practice constitute a strong incentive for the teachers to invest in their participation and endeavor to learn more and do better.

"I occupy myself a lot, in a good sense, through participation, by taking part, so that by participating it enables the group to be not only be two or three people from the first or second cycles, so that everyone feels motivated, useful, professionally secure (...).” (PB)

However, besides professional security, these experiences can evoke confidence and the privilege (Wenger, McDermott \& Snyder, 2002) of belonging to a community of practice that strengthens professional development, as it relates to the teacher:

"When there is a basis of confidence (...) and a desire for knowledge, this combines and here inside one can get to learn with each other and we can obtain results and strategies for being better." (PB)

Dealing with the research of Wenger (1998) and from aspects mentioned by the teachers involved in this study it can be inferred that the communities of practice are communities of sharing and learning, which are sufficiently complex that they can present very diverse peculiarities, whether big or small, and that they can last more or less over time. Their elements can be shared in the same geographical location or not and they can be homogeneous or heterogeneous, spontaneous or intentional; and, lastly, they can be perfectly institutionalized or not, as well as being recognized or not at all by the schools. In this way and in keeping with the claims of Alves, Queirós and Batista (2017) what is important is that none of them would be considered, as more or less valuable, since all of them contribute to the construction and sharing of new knowledge in a more adequate way with respect to the context into which they fit.

\section{How teachers work and learn}

One of the important factors inherent in collaborative learning and to the organization of communities of learning concerns the way that teachers work, particularly, in relation to teacher collaboration in their work place. For this purpose, we analyzed various dimensions such as: the structures, contexts and levels of collaboration; the factors that facilitated or made difficult the respective teacher collaboration; the role of formal meetings; the practices in which the teachers become involved for learning; and the mechanisms for monitoring the work of teachers.

In a general way the teachers said that they had teacher collaboration in different contexts and educational structures promoted predominantly by moments of continuous training but fundamentally by projects and pedagogical encounters. In due time some teachers stressed that, although this collaboration takes shape at various levels and happens whether in formal settings or in informal contexts, in practice there are some subject groups that are more collaborative than others. Also the importance of collaboration between equals should be emphasized, as a strategy for the development of teacher learning.

In their turn, other teachers highlighted the lack that they felt with respect to the absence of this practice in their everyday life, which reinforced the perception of its relevance in professional development in accordance with Figure 2. 


\section{TEACHER COLLABORATION}

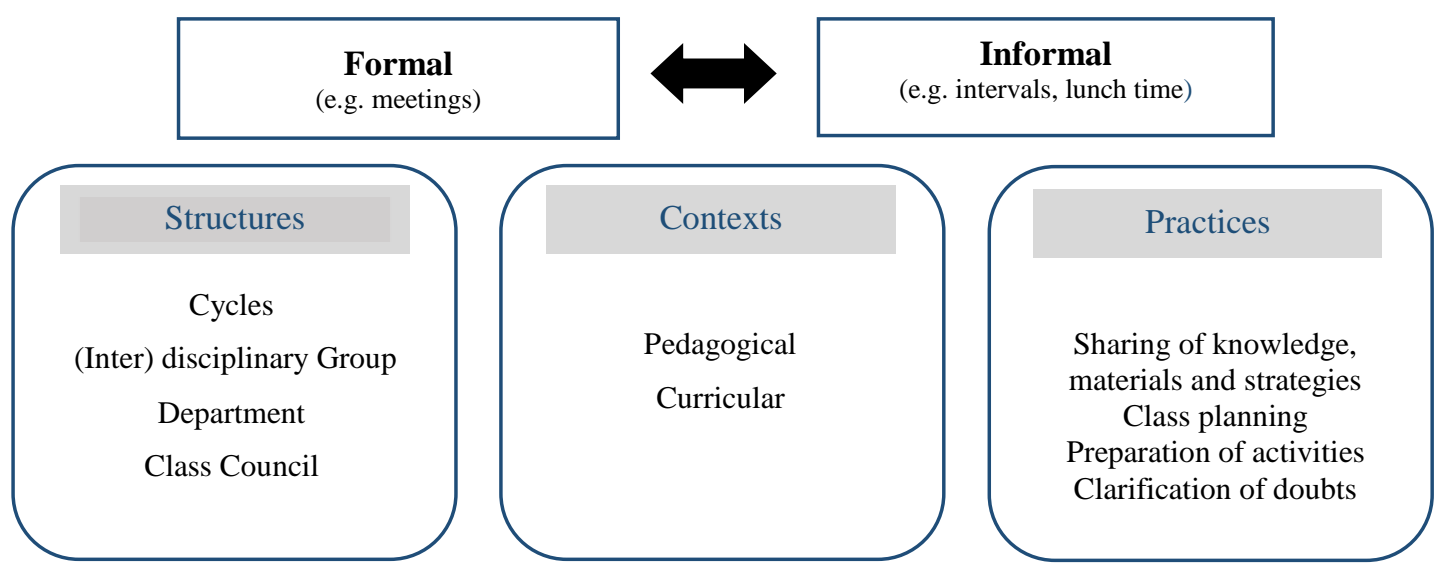

Figure 2:-Contexts and practices of teacher collaboration

The excerpts that follow complement the information organized in the figure above.

"Until right now, even in the change from the first cycle to second cycle, there is already a very major curricular articulation" (PB)

"With colleagues the fact is of our being all involved in the same project and working very closely together, so the sharing is daily $(\ldots)$ " $(\mathrm{PH})$

"(...) we finish by organizing all the work, the strategies... we finish by having conversations more at the level of preparation of activities, about how to write very specific questions to encourage the students in their learning." $(\mathrm{PH})$

"(...) there are always those moments of sharing of ideas, what he did during the past year, what will I do this year, how the students progress, will they regress or not, so we have these moments and in terms of collaborative work it is constant - be it formal or informally." (PH)

With respect to the factors that drive teacher collaboration, 95 of the 134 teachers of the Group (71\%) responded to a questionnaire using a Lickert-type scale, where they were asked about the degree of agreement (totally disagree to totally agree) considering a set of factors concerning collaboration. Table 4 allows us to show levels of positive agreement from the scale ("Agree" e "Agree totally") in all of the dimensions presented, thus emphasizing the articulation existing between the pedagogical structures, the contexts and the practices developed between equals. Therefore, analyzing the statements related to the factors of collaboration present in the enquiry questions used in the scale, one can understand that the responses corroborated the perceptions mentioned by the teachers during the interviews, thus showing that the practice of collaborative work was essentially in situations that concerned the planning of school activities (97.9\%) and the sharing of ideas and teaching material (95.8\%).

\begin{tabular}{|c|c|c|c|c|c|c|c|}
\hline \multirow{2}{*}{\multicolumn{2}{|c|}{ FACTORS OF COLLABORATION }} & \multicolumn{2}{|c|}{$\begin{array}{ll}\text { NEITHER } \\
\text { AGREE NOR } \\
\text { DISAGREE }\end{array}$} & \multicolumn{2}{|c|}{ AGREE } & \multicolumn{2}{|c|}{$\begin{array}{l}\text { AGREE } \\
\text { TOTALLY }\end{array}$} \\
\hline & & $\%$ & No. & $\%$ & No. & $\%$ & No. \\
\hline 1 & $\begin{array}{l}\text { The teachers work together on planning activities } \\
\text { at the school level. }\end{array}$ & 1,1 & 1 & 54,7 & 52 & 43,2 & 41 \\
\hline 2 & Generally teachers in my department work & 3,2 & 3 & 60,0 & 60 & 35,8 & 34 \\
\hline
\end{tabular}




\begin{tabular}{|c|c|c|c|c|c|c|c|}
\hline & collaboratively. & & & & & & \\
\hline 3 & $\begin{array}{l}\text { Generally my subject group of teachers works } \\
\text { collaboratively. }\end{array}$ & 5,4 & 5 & 63,0 & 58 & 30,4 & 28 \\
\hline 4 & $\begin{array}{l}\begin{array}{l}\text { Generally teachers in my school work } \\
\text { collaboratively. }\end{array} \\
\end{array}$ & 5,3 & 5 & 48,4 & 46 & 43,2 & 41 \\
\hline 5 & $\begin{array}{l}\text { Generally in my class council teachers work } \\
\text { collaboratively. }\end{array}$ & 14,8 & 13 & 58,0 & 51 & 27,3 & 24 \\
\hline 6 & $\begin{array}{l}\text { In my school teachers share ideas and teaching } \\
\text { materials. }\end{array}$ & 2,1 & 2 & 55,8 & 53 & 40,0 & 38 \\
\hline
\end{tabular}

Table 4:- Factors of teacher collaboration

Throughout the interviews, these factors were stressed by the teachers, as is exemplified by the following comments: "But there is always a very big collaboration and even at the level of content we share a lot. There is a lot of such collaboration here among us.” (PD);

"(...) we even exchange instruments of evaluation. I offer any other document that could bring an added value to the department and it is taken up pedagogically." (PE).

It should be emphasized that $14.8 \%$ of the respondents placed themselves in a neutral position in relation to the degree of their agreement with collaboration at the level of the school council. Although it was not actually a large percentage, it is important to point out that in the interviews undertaken the collaboration at this level was also one of the aspects mentioned as something to work and improve on in the School Group, as was stated in the following excerpts:

"While before that I worked more, for example, with those colleagues with whom I got along with more, later on we started also to work at the level of the class council. Only it was not good but already it was leading towards success (...)." (PD)

"At this moment let us see, we are trying that it should be at the level of the class council. Still it is not like that... still it is not such that I can say "it is running well!", no. We are just starting." (PD).

The words of the teachers interviewed underlined that teacher collaboration brought about positive effects in the improvement of their pedagogical practices, thus showing recognition of the importance of this process for their professional development in the work context.

With reference to the learning contexts of teachers, there are associated tasks in which the teachers involve themselves for learning. The teachers interviewed referred to a group of tasks carried out individually and in a group that can be found in Table 5. It proved to be true that there was a certain complimentarity between the tasks of a more individual character and collective work, which also showed the diversity of the indicated contexts and activities that - in the understanding of the teachers - strengthened professional learning

\begin{tabular}{|c|c|c|}
\hline \multirow[t]{4}{*}{ i) Individual tasks } & Individual reflection & \multirow{10}{*}{$\begin{array}{l}\text { "(...) I use all of the bibliography to prepare my } \\
\text { training, which always ends up more by being a way } \\
\text { of clearing up my doubts (...)" (PH); } \\
\text { "(...) I continue with the same way to study, if I can } \\
\text { say that, because I continue to read I continue to ... at } \\
\text { this moment to finish off the development of another } \\
\text { investigation at the post-doctoral level and I am } \\
\text { continuing to study (...)" (PB); } \\
\text { "Even with the children I sometimes learn ... even the } \\
\text { other day in science they gave me a lesson. And it is } \\
\text { like this, we learn together." (PD); } \\
\text { "(...) with respect to training actions, I feel that I have } \\
\text { gaps and that I needed more help about something." } \\
\text { (PG); } \\
\text { "The others can be on training, in a training center, it } \\
\text { can be my colleagues from a meeting, it can be my }\end{array}$} \\
\hline & Reading articles/studies & \\
\hline & Researching on Internet & \\
\hline & Academic training & \\
\hline \multirow{6}{*}{$\begin{array}{l}\text { ii) Collective } \\
\text { tasks }\end{array}$} & Reflection in groups & \\
\hline & $\begin{array}{l}\text { In the context of working } \\
\text { with colleagues }\end{array}$ & \\
\hline & $\begin{array}{l}\text { In the context of working } \\
\text { with students }\end{array}$ & \\
\hline & Pedagogical projects & \\
\hline & $\begin{array}{l}\text { Scientific events } \\
\text { (congresses, symposia, } \\
\text { etc) }\end{array}$ & \\
\hline & Training actions & \\
\hline
\end{tabular}




\begin{tabular}{|l|l|l|}
\hline & $\begin{array}{l}\text { colleagues from the school management, it can be my } \\
\text { colleagues from school, colleagues from another } \\
\text { school, it can be a conference, a congress, a } \\
\text { symposium, a round table with university professors, } \\
\text { specialists and from readings. I also like viewing a } \\
\text { television program, where some news also might } \\
\text { provoke me, so I like to be by myself and to have time } \\
\text { to appreciate my individual reflections." (PB); } \\
\text { "Now that I learn a lot more with the others, I do not } \\
\text { have doubts anymore." (PD). }\end{array}$ \\
\hline
\end{tabular}

Table 5:-Tasks in which the teachers were involved for learning

Another question identified in the interviews related to the strategies for the monitoring of the work of teachers. The studies developed by Tucker and Stronge (2007) reveal that professional teacher performance has direct implications for the educational success of students, because much of that success depends on the personal and professional qualities of the teachers. These studies reinforce the view that pedagogical knowledge, the capacity to utilize a wide range of teaching strategies with skill and competence, as well as enthusiasm for education, which has been acquired by teachers throughout their career, leads to the success of the students. In this way the monitoring of the work of teachers reveals an element of important analysis that normally falls back on the frequency of training actions, on supervision and on teacher collaboration in formal and/or informal contexts with other teachers.

In this area teachers are unanimous in stressing that the frequency of training actions, their involvement in projects and the pedagogical acquaintanceship in the classroom with teaching assessors and assistants assumes a prominent place in the monitoring of teaching work.

“(...) a project that I saw, that turned out to be part of experimental sciences, made experiments together in accordance with the themes on which we were going to work. I liked to participate (...) in another project where we had to understand new technologies but was a collaborative work... it had people that I did not know who they were and that I did not know at all and with whom we did work at a distance. " $(\mathrm{PH})$

“(...) the teacher assessors helped in a sort of tutelage of equals, we met with these teachers that had those operational difficulties together with colleagues, who performed more easily and knew about what was expected. It was a way of improving the level of these colleagues." (PA)

“(...) for some two, three years I participated in a training in school in which we reflected about the value of collaborative work and other things (...). (PI)

Collaborative learning, as a superior form of learning, has been adopted by schools and by teachers. Nevertheless, it is still not recognized nor given a central place in school culture. In this sense Meirinhos (2010) reinforces the view that learning in communities of practice does not impede self-training - the capacity of each one learn to by him/herself - but it implies involvement in a group that reflects, shares, learns with others and applies what is learned, so that its work produces success in student learning.

\section{Conclusion:-}

Following an analysis of the results of this study we concluded that more and more schools require the creation of a culture of permanent learning in which knowledge is constructed socially, thus assigning a significant importance to the communities that learn within the dynamics of collaborative learning.

This way the collaborative processes, which are inseparable from learning in communities of practice and the respective dynamics of learning in a community, are related to the concept of learning, as an individual process that now is starting to be a shared social process.

The communities of practice and the respective dynamics of collaborative learning are not yet a widely implemented process in schools and this reflects characteristics of the organizational structure and culture of schools. However, the first steps are starting to made in this direction and experiments in the educational contexts are beginning to emerge, as is exemplified by the target group of this study. 
The teachers, who are motivated by the challenges that they face on a daily basis, are coming together in working groups and are forming communities of practice and of learning, as they see in them the possibility of finding responses to the transformations imposed on them by the society of knowledge. Yet, although the teachers have recognized the characteristics of the communities of practice and collaborative learning, they do not associate these with their experiences of the concept of a 'community of practice', which is not familiar to them.

In these communities of collaborative learning, the teachers feel involved in certain projects, actions or common ideas by sharing a relative understanding of what they are doing or know and this has positive consequences for the process of student learning. For teachers the communities of practice and collaborative learning are spaces of reflection, production, construction and reconstruction of concepts, opinions and knowledge, through their vigorous and implicit questioning of all in which they participate. It is highlight that the creation and/or continuity of the communities of practice in current educational contexts will only happen in view of the commitment and dedication, good will and investment on the part of the teachers, who are frequently worn out and exhausted. However, it is possible, as demonstrated by the results of this study.

In relation to the modes of working of teachers they themselves have identified facilitating factors, such as interpersonal relationships and project work, as well as others that inhibit the development of a collaborative culture in educational contexts, like lack of time, demotivation, professional exhaustion and the new professional demands with their consequences for learning and student success. Still in this area, the teachers mentioned the importance of continuous training and collaborative work in the development and monitoring of their work.

\section{Acknowledgements:-}

Thanks are due to COMPETE: POCI-01-0145-FEDER-007560 and FCT [Fundação para a Ciência e Tecnologia] (The Portuguese Government Fund for Science and Technology) within the Project Scope: UID/CCI/00736/2019 for funding to support the translation of this study.

\section{Bibliographic References:-}

1. Alves, M., Queirós, P. \& Batista, P. (2017). O valor formativo das comunidades de prática na construção da identidade profissional. Revista Portuguesa de Educação, 30 (2), 159-185.

2. Bryman, A. (1988). Quantity and quality in social research. London: Routledge.

3. Coll, C. (2004). Las comunidades de aprendizaje. Nuevos horizontes para la investigación y la intervención en psicología de la educación. In the report of the IV Congreso Internacional de Psicología y Educación, Almeria.

4. Justino, D. (2010). Difícil é educá-los. Lisboa: Fundação Francisco Manuel dos Santos.

5. Meirinhos, M. (2010). Comunidades de prática de desenvolvimento Profissional: Condições e Desafios de Emergência. In Osório, A. M. (Ed.), Infância no digital. Sesimbra: ArcaComum, 219-234. Available at:https://bibliotecadigital.ipb.pt/bitstream/10198/4398/1/Arca_meirinhos.pdf (1 Jull2018).

6. Santos, M. P. (2012). Comunidades de prática e bibliotecas escolares. Lisbon: RBE. Available at: http://www.rbe.min- edu.pt/np4/np4/?newsId=649\&fileName=978_972_742_360_6.pdf.(25 August 2018).

7. Silva, A. (2004). Aprendizagem e Comunidade de Prática. Available at: http://www.bocc.uff.br/pag/silvaadelina-aprendizagem-e-comunidade.pdf (31 August 2018).

8. Stake, R. E. (1995). The art of case study research. Thousand Oaks: Sage Publications.

9. Wenger, E. (1998). Communities of practice: learning, meaning, and identity. New York: Cambridge University Press.

10. Tucker, P. D. \& Stronge J. H. (2007). A avaliação dos professores e os resultados dos alunos. Porto: Edições ASA.

11. UNESCO (2016). Repensar a Educação: rumo a um bem comum mundial?. Brasília: UNESCO. Available at: http://unesdoc.unesco.org/images/0024/002446/244670POR.pdf.Accessed on 4 September 2018.

12. UNESCO et al. (2016). Educação 2030: Declaração de Incheon e Marco de Ação: rumo a uma educação de qualidade inclusiva e equitativa e à educação ao longo da vida para todos. Brasília: UNESCO. Available at: http://unesdoc.unesco.org/images/0024/002432/243278POR.pdf. Accessed on 4 September 2018.

13. Yin, R. K. (1994). Case Study Research. Design and Methods. Newbury Park: SAGE Publications, Applied Social Research Methods Series, Vol. 5. 